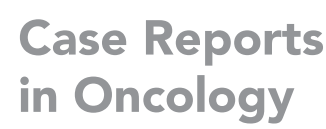

Case Reports

\title{
Lung Adenocarcinoma during Pregnancy: 11-Year Follow-Up
}

\author{
Angel Acosta Rojas ${ }^{a}$ Ana Collazo-Lorduy ${ }^{b}$ Jordi Remon ${ }^{c}$ \\ Ovidio Hernando Requejo ${ }^{a}$ Beatriz Jiménez-Munarriz ${ }^{b}$ \\ María Carmen Rubio Rodríguez ${ }^{a}$ Javier De Castro ${ }^{b}$ \\ aDepartment of Radiation Oncology, Hospital Universitario Madrid Sanchinarro-CIOCC, \\ Madrid, Spain; bepartment of Medical Oncology, Hospital Universitario Madrid \\ Sanchinarro-CIOCC, Madrid, Spain; 'Department of Medical Oncology, ClOCC-Barcelona \\ Hospital HM Delfos, Barcelona, Spain
}

\section{Keywords}

Adenocarcinoma - ALK inhibitors · Cancer and pregnancy · Lung cancer · Radiation therapy · Radiosurgery $\cdot$ Targeted therapy

\section{Abstract}

The incidence of lung cancer during pregnancy is rising due to the high rate of smokers in young women and the late mean age of pregnancy; in addition, considering that the patients are young women with a higher incidence of molecular alterations, molecular testing in lung adenocarcinoma should always be performed, even in pregnancy. Here, we report the case of a lung adenocarcinoma diagnosed during pregnancy with a long survival who benefitted from brain radiotherapy, conventional chemotherapy, and ALK TKI-targeted treatment. It reveals the safety of whole brain radiotherapy during pregnancy and consideration of other brain radiation techniques even in palliative cases, which should be personalized and managed by a multidisciplinary team. However, upfront management of brain metastasis in ALKpositive patients remains unresolved.

\section{Introduction}

The incidence of non-small-cell lung cancer during pregnancy is still uncommon but rising [1]. Chemotherapy remains the current standard treatment during pregnancy but it correlates with poor outcome and prematurity [2]. 


\section{Case Reports in Oncology}

\begin{tabular}{l|l}
\hline Case Rep Oncol 2020;13:892-895 \\
\hline DOI: 10.1159/000508360 & $\begin{array}{l}\text { @ 2020 The Author(s). Published by S. Karger AG, Basel } \\
\text { www.karger.com/cro }\end{array}$ \\
\hline
\end{tabular}

Acosta Rojas et al.: Lung cancer in pregnancy

Fig. 1. Sequential CT evolution and response to systemic treatments. Metastatic pulmonary nodules, visible in the circle, 2 weeks after carboplatin-pemetrexed combination therapy (a). Partial response on maintenance pemetrexed after 2 months (b), 26 cycles (c), 32 cycles (d), and 42 cycles (e). Disease became stable when our patient was started on crizotinib (f), almost complete response on crizotinib (g), and stable disease when crizotinib was discontinued (h).

Fig. 2. Brain MRI for radiotherapy planning and radiosurgery dosimetry plan. 3D T1 contrast sequence MRI showing some of the brain metastases was fused with planning-CT for radiosurgery, planned with thermoplastic masks and a frameless localization system using dynamic-arc therapy technique isocentrically with 3-5 arcs formed with multiple microlamines and $6 \mathrm{MV}$ photons.
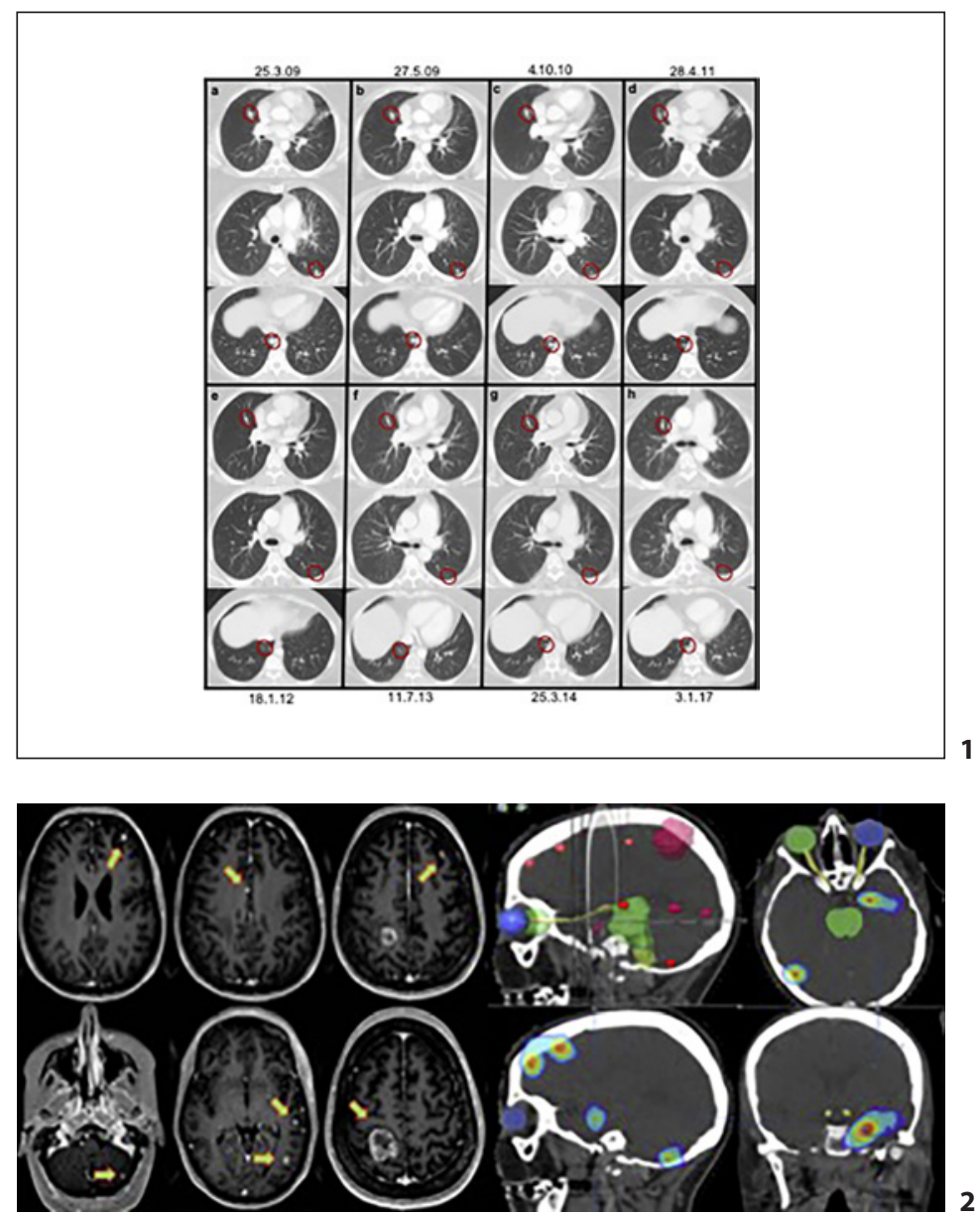

Nowadays, in targetable oncogenic addicted tumors, personalized targeted approaches mainly specific tyrosine kinase inhibitors (TKIs) - improve the outcome, and routine tumor genomic profiling has become a new standard of care [3], even during pregnancy, as some of these genomic alterations are more common in younger and never-smoker patients. In contrast, pharmacological data of these drugs in pregnant women and fetuses, and long-term follow-up of exposed children, have not yet been reported.

\section{Clinical Report}

A 31-year-old woman, never-smoker, with a 16-year history of systemic lupus erythematosus, and an episode of cerebral pseudotumor in 2000, was admitted to the emergency department in October 2008 at 23 weeks of gestation with left-sided numbness, paresthesia, and 3-kg weight loss. Her physical examination was otherwise unremarkable.

Blood tests and EEG were normal; neck Doppler ultrasonography ruled out vascular abnormalities but showed multiple left supraclavicular lymphadenopathies. Trucut-biopsy was performed, and the results concluded metastatic adenocarcinoma, EGFR status wildtype.

A CT scan showed multiple brain metastases (BM), multiple bilateral lung nodules, mediastinal lymphadenopathies, pericardial effusion, and lymphangitis carcinomatous. Her abdominal ultrasound was normal. 
Based on the diagnosis of advanced EGFR-wild type lung adenocarcinoma, a multidisciplinary team decided to start treatment with whole brain radiotherapy in order to control the neurological symptoms, administering 30 Gy in 10 fractions, with in vivo abdominal thermoluminescence dosimetry (total dose: 26 millisievert). No other cancer therapy was prescribed until delivery. At 32 weeks of gestation, a healthy girl was delivered by Cesarean section; however, a CT scan reported progression of the pericardial effusion requiring drainage without progression on brain MRI.

Six cycles of carboplatin and pemetrexed were administered (Fig. 1a), followed by maintenance pemetrexed achieving a partial response (Fig. 1b-d).

In May 2009, 9 stable BM were treated with radiosurgery with consolidative intention and partial response in the rest of the BM, administering $18 \mathrm{~Gy}$ to the biggest metastasis of $3 \times 3 \times 3.5 \mathrm{~cm}$ and 21 Gy to the remaining 8 , all in single fractions delivered on alternating days (Fig. 2). No acute toxicity was reported.

In December 2010, after 28 cycles of maintenance chemotherapy, she experienced paresis of the left leg. MRI discarded spinal disease and showed stable BM. Her symptoms persisted despite dexamethasone, so the right parietal lesion was excised, and histopathology confirmed radionecrosis. However, her symptoms did not improve. Therefore, bevacizumab was added to pemetrexed with some effect. She received 43 cycles of pemetrexed (Fig. 1e) and 7 cycles of bevacizumab in total.

In April 2012 with disease stable, ALK rearrangement was confirmed in a new tissue biopsy, and the patient was switched to crizotinib (Fig. 1f), which controlled the disease for 5 years. In February 2017, after 5 years of unexpected survival, radiological evaluation showed stable disease, but crizotinib was discontinued (Fig. 1h) as a consequence of neurological and clinical deterioration not suitable for being treated with subsequent ALK TKI or local strategies.

Currently, our patient is slowly deteriorating at home under palliative care. During her last radiological assessment in July 2019, a new BM of $14 \mathrm{~mm}$ was detected. The rest of the disease is stable.

\section{Discussion and Conclusions}

To our knowledge, we report the first case of $A L K$-positive lung adenocarcinoma diagnosed during pregnancy with 11 years of overall survival, who benefitted from local strategies, chemotherapy, and just one line of first-generation ALK TKI. In addition, this case reveals the safety of whole brain radiotherapy administered during pregnancy and the efficacy of others definitive radiation techniques that should be considered even in the palliative setting.

This case reflects that genomic profiling is mandatory in all advanced non-small-cell lung cancer patients, and upfront treatment of BM in ALK-positive patients remains unresolved (whole brain radiotherapy - stereotactic radiosurgery vs. new generation ALK TKI). However, the long-term benefit/toxicity ratio is relevant for making upfront decisions.

At the time of diagnosis of our case, evaluation of $A L K$ rearrangement has not already been described. Today, probably based on the remarkable long-term survival of ALK-positive patients, therapeutic strategy would be to start treatment with next-generation ALK TKI, with increased intracranial activity [4,5], and postpone brain radiotherapy for as long as possible, thus delaying the potential neurological toxicity, which can limit the administration of sequential strategies with ALK TKI.

Moreover, cancer during pregnancy must be managed in specialized centers under multidisciplinary team care for optimal outcomes of mother and child.

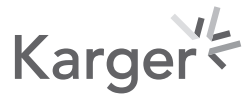




\section{Case Reports in Oncology}

\begin{tabular}{l|l}
\hline Case Rep Oncol 2020;13:892-895 \\
\hline DOI: 10.1159/000508360 & $\begin{array}{l}\text { ○ 2020 The Author(s). Published by S. Karger AG, Basel } \\
\text { www.karger.com/cro }\end{array}$ \\
\hline
\end{tabular}

Acosta Rojas et al.: Lung cancer in pregnancy

\section{Statement of Ethics}

The authors certify that they have obtained all appropriate patient consent forms. In the form, the patient has given her consent for her images and other clinical information to be reported in the journal. The patient understands that her name and initials will not be published, and due efforts will be made to conceal her identity, but anonymity cannot be guaranteed.

\section{Conflict of Interest Statement}

The authors declare no conflicts of interest.

\section{Funding Sources}

This research did not receive any specific grant from funding agencies in the public, commercial, or not-for-profit sector.

\section{Author Contributors}

A.A.R., A.C.-L., and B.J-M. had full access to all of the data in the study and take responsibility for the integrity of the data and the accuracy of the data analysis. A.A.R., A.C.-L., and B.J-M.: study concept and design. A.A.R., A.C.-L., B.J-M., and O.H.R.: acquisition, analysis, or interpretation of data. J.R., A.A.R., and A.C.-L.: drafting of the manuscript. All authors: critical revision of the manuscript for important intellectual content. A.A.R. and A.C.-L.: administrative, technical, or material support. A.C.-L.: study supervision.

\section{References}

1 Stensheim H, Møller B, van Dijk T, Fosså SD. Cause-specific survival for women diagnosed with cancer during pregnancy or lactation: a registry-based cohort study. J Clin Oncol. 2009;27(1):45-51.

2 Peccatori FA, Azim Jr HA, Orecchia R, Hoekstra HJ, Pavlidis N, Kesic V, et al. Cancer, pregnancy and fertility: ESMO Clinical Practice Guidelines for diagnosis, treatment and follow-up. Ann Oncol. 2013;24(6):vi160-70.

3 Novello S, Barlesi F, Califano R, Cufer T, Ekman S, Levra MG, et al. Metastatic non-small-cell lung cancer: ESMO Clinical Practice Guidelines for diagnosis, treatment and follow-up. Ann Oncol. 2016;27(Suppl 5):v1-27.

4 Nishio M, Nakagawa K, Mitsudomi T, Yamamoto N, Tanaka T, Kuriki H, et al. Analysis of central nervous system efficacy in the J-ALEX study of alectinib versus crizotinib in ALK -positive non-small-cell lung cancer. Lung Cancer. 2018;121:37-40.

5 Lenderking WR, Lin H, Speck RM, Zhu Y, Huang H, Huang J, et al. Patient-reported outcomes and quality of life in advanced ALK+ non-small-cell lung cancer trial of brigatinib (ALTA). Future Oncol. 2019;15(24):2841-55. 